\title{
The Impact of Insomnia Symptoms on Risk Factors of Metabolic Syndrome among the Urban Elderly in Northern Taiwan
}

\author{
Meng-Ting Tsou \\ Family Medicine, Mackay Memorial Hospital, Taiwan \\ Email: mttsou@gmail.com, mttsou@mmh.org.tw
}

Received 29 September 2015; accepted 14 October 2015; published 22 October 2015

Copyright (C) 2015 by author and OALib.

This work is licensed under the Creative Commons Attribution International License (CC BY).

http://creativecommons.org/licenses/by/4.0/

(c) (i) Open Access

\begin{abstract}
Sleep complaints played a role in predicting the development of metabolic syndrome (MetS) in the general population. This cross-sectional survey was performed among elderly people (age $\geq 65$ years) who underwent a health examination for senior citizens since March 2009 to November 2009. 1181 participants were surveyed, including 433 men (36.7\%) and 748 women $(63.3 \%)$. We aimed at the association between self-reported insomnia symptoms and risk factors of MetS in the elderly population living in northern Taiwan. The modified National Cholesterol Education Program-Adult Treatment Panel III (NCEP-ATP III) was used for criteria of MetS. Logistic regression examined the impact on the MetS and its components according to individual insomnia symptoms and syndrome. The result showed that difficulty falling asleep (DFA), a specific symptom of insomnia, was significantly associated with MetS (OR: 1.42, 95\% CI = 1.09 - 1.86). DFA increased the risk of abdominal obesity, hyperglycemia, and hypertriglycemia. Frequent waking from sleep or dreamy increased the risk of abdominal obesity. Difficulty staying sleep increased the risk of hypertension. Other insomnia symptoms (non-refreshing sleep) were not associated with the increased risk of any MetS factors. Insomnia symptoms, including DFA, difficulty staying sleep, and frequent waking from sleep or dreamy increased the odds ratio of risk factors. Evaluating insomnia symptoms can help identify individuals that are at risk of MeS.
\end{abstract}

\section{Keywords}

Metabolic Syndrome, Insomnia, Risk Factor, Elderly Taiwanese

Subject Areas: Metabolic Sciences

\section{Introduction}

In 2011, in Taiwan, cardiovascular heart disease (CHD), cerebral vascular accident (CVA), and diabetes were

How to cite this paper: Tsou, M.-T. (2015) The Impact of Insomnia Symptoms on Risk Factors of Metabolic Syndrome among the Urban Elderly in Northern Taiwan. Open Access Library Journal, 2: e2013.

http://dx.doi.org/10.4236/oalib.1102013 
the $2^{\text {nd }}, 3^{\text {rd }}$, and $5^{\text {th }}$ leading causes of death in general population, respectively [1]. Metabolic syndrome (MetS) is closely associated with these diseases and increases their risk [2]-[5]. The Elderly Nutritional and Health Survey in Taiwan (NAHSIT-II, 1999-2000, $\mathrm{N}=2432$ ), a national survey of non-institutionalized elderly Taiwanese (age $\geq 65$ years), showed that $21.5 \%$ of elderly men and $37.6 \%$ of elderly women had MetS [6] [7]. The prevalence of MetS increased progressively as seen in the NAHSIT $(2005-2008, \mathrm{~N}=897)$ data where $30.2 \%$ of men and $48.9 \%$ of women surveyed met the criteria for MetS [2]. These results showed that it was critical for public health to identify the modifiable risk factors associated with the development of MetS.

Many prospective studies have proved an independent relationship between insomnia symptoms and the increased risk of developing individual components of MetS, including obesity, hypertension, glucose intolerance, and diabetes [8]-[13]. A 2010 prospective study examined the relationship between sleep disturbances that commonly presented in clinical practice and predicted the development of the MetS [14]. That study stressed that sleep problems were not just a simple annoyance, but they had potential serious ramifications on public health. Several cross-sectional studies have shown that a broader range of self-reported insomnia complaints, as well as polysomnographically assessed insomnia architecture are associated with MetS [15]-[19]. In this cross-sectional study, we used a questionnaire with a broader range of self-reported insomnia complaints to discuss the relationship between insomnia symptoms and MetS in the elderly from northern Taiwan.

In another study using same database, we found that difficulty falling asleep and unhealthy personal sleep hygiene habits increased the number of MetS risk factors [20]. We continued another goal in this study which investigated the relationship between insomnia symptoms and the component factors of MetS (hyperglycemia, central adiposity, hypertension, hypertriglyceridemia, and low high density lipoprotein cholesterol) in the same population. We used the insomnia syndrome and symptoms, which included insomnia complaints with reported daytime impairment, and the Chinese version of the Athens Insomnia Scale (CAIS) [21]. The criteria for MetS were defined using the modified National Cholesterol Education Program-Adult Treatment Panel III (NCEPATP III) [22]. In this paper, we explore whether the relationship between insomnia symptoms and MetS can expose other risk factors for MetS and its components in an elderly community of northern Taiwanese.

The results of the study indicate that insomnia symptoms should be taken seriously by healthcare professionals, and common insomnia complaints should be checked while assessing any elderly patient.

\section{Methods}

\subsection{Study Population}

This study included elderly individuals (age $\geq 65$ years) who underwent a health examination since March 2009 to November 2009 at one medical center in Taipei City. A total of 1799 elderly individuals received physical examinations in the hospitals. Data were collected using a questionnaire completed by the interviewer in a face-to-face session in order to avoid write-in errors. After 420 cases were excluded due to incomplete questionnaires, a total of 1379 cases were included for data analysis. Another 198 cases were eliminated, due to incomplete data on the 5 risk factors of MetS. In the end, a total of 1181 complete data sets (recovery rate of 85.6\%) were used. All subjects provided written informed consent approved by the Institutional Review Board of our hospital, and the study was issued the project research number 09MMHISO11.

\subsection{Data Collection}

During the visit, a $12 \mathrm{~h}$ fasting blood draw was collected, sitting blood pressure (BP) and anthropometric measurements were made. After the participant had sat and rested for 5 - 10 min, BP readings were taken twice in the right arm 30 seconds apart. If the first two BP readings differed by more than $10 \mathrm{mmHg}$, a third $\mathrm{BP}$ measurement was made. The average of the two closest readings was calculated and used in the analysis [23]. Waist circumference was measured at the standard point at the end of a relaxed expiration with a tape measure placed parallel to the floor with the participants standing arms outstretched [24]. Plasma sample was collected for analysis of fasting plasma glucose (FPG), and serum was collected for lipid measurements. Fasting total cholesterol, triglyceride (TG), and FPG were measured by an automated system (Vitros 550/750, Ortho-Clinical Diagnostics Inc., a Johnson and Johnson Company, Rochester, NY, USA). Electrophoresis was performed to measure highdensity lipoprotein cholesterol (HDL-C). 


\subsection{Diagnostic Criteria for MetS}

Modified NCEP-ATPIII criteria were used in this study. MetS was defined as the presence of any 3 of the following 5 conditions: abdominal obesity (AO; waist circumference, $\geq 90 \mathrm{~cm}$ for men and $\geq 80 \mathrm{~cm}$ for women), hyper triglyceremia (HTG; TG, $\geq 150 \mathrm{mg} / \mathrm{dl}$ ), low serum HDL-C (HDL-C, $\leq 40 \mathrm{mg} / \mathrm{dl}$ for men and $\leq 50 \mathrm{mg} / \mathrm{dl}$ for women), hypertension (HT; systolic BP, $\geq 130$, diastolic $\mathrm{BP}, \geq 85 \mathrm{mmHg}$, or the use of antihypertensive agents), and hyperglycemia (HG; FPG, $\geq 100 \mathrm{mg} / \mathrm{dl}$ or the use of anti-hyperglycemic agents) [22].

\subsection{Insomnia Symptoms/Insomnia Syndrome}

The CAIS (Chinese version of the Athens Insomnia Scale) is a self-report instrument designed to screen for insomnia symptoms that occur with a frequency of $\geq 3$ times per week, which were experienced in the past month and are associated with the diagnostic criteria for primary insomnia. CAIS-5 demonstrated the items 1-5 of the AIS (nighttime symptoms) are fair tools for screening and diagnosing insomnia in clinical practice, and they have satisfactory reliability and validity. Responses were rated on a scale from 0 to 3 , the score $\geq 2$ was included in our study. Correlation coefficients of test-retest reliability were $0.84-0.86$. The suggested cutoff points for insomnia among this ethnic Chinese population are 5 for the CAIS-5 (area under the curve $[$ AUC] $=0.90, \mathrm{p}<$ $0.01)[21]$.

The presence of insomnia symptoms, included at least 1 insomnia-related sleep complaint (difficulty falling asleep, difficulty staying asleep, sleep is not refreshing, or frequent waking from sleep or dreamy), with a frequency criteria of $\geq 3$ times per week. The insomnia duration was divided into five groups: $<1$ month, 1 month $1 / 2$ year, $1 / 2$ year -1 year, 1 - 3 years, and $>3$ years.

\subsection{Brief Symptom Rating Scale}

Mental health was screened using the Brief Symptom Rating Scale (BSRS-5). This self-rated questionnaire requires respondents to report whether they had felt tense, blue, irritated, inferior, or had trouble falling asleep in the past week. Responses were rated on a scale from 0 to 4 , with 0 being "not at all" and 4 being "extremely." Total scores ranged from 0 to 20 [25] [26].

Internal consistency (Cronbach's $\alpha$ ) coefficients of the BSRS-5 were $0.77-0.90$. The test-retest reliability coefficient was 0.82 . When a score of $\geq 6$ was used as the cut-off score for psychiatric casec, the rate of accurate classification of the BSRS-5 was $76.3 \%$ (78.9\% sensitivity, $74.3 \%$ specificity, $69.9 \%$ positive predictive value, $82.3 \%$ negative predictive value) [25].

\subsection{Other Covariates}

Other demographic histories, including sex, education level, and living conditions, were collected at this visit. Education level was classified as 1 of the following 5 levels: illiterate, elementary school, junior high school, senior high school, and college or higher; living condition was defined as single or living with family.

Physical activity was assessed by the Lipids Research Clinics Questionnaire and analyzed as a categorical variable (sedentary versus non-sedentary lifestyle) [27]. Other lifestyle characteristics, including smoking history (current or former smoker versus never a smoker) and alcohol consumption ( $>4$ drinks per week versus $\leq 4$ drinks per week) were measured by study-specific questionnaires (MetS and insomnia, sleep).

\section{Statistical Methods}

SAS 9.0 software (SAS Inc., Cary, NC, USA) and SPSS 17.0 (SPSS Inc., Chicago, IL, USA) were used for statistical analysis. Continuous variables are reported as mean \pm standard deviation (SD), and categorical variables are reported as number and percentage. Differences in baseline demographic, psychosocial, lifestyle characteristics, and sleep measures were compared between those who had metabolic syndrome versus those who did not by use of $\chi^{2}$ tests for categorical variables and student $t$-tests for continuous variables. Multivariate logistic regression was used to examine the relationship between individual sleep symptoms or insomnia syndrome and the risk of the metabolic syndrome, with adjustment for covariates including age, sex, living status, smoking status, alcohol consumption, sedentary lifestyle, and depression status. The relationships among sleep symptoms and the individual components of metabolic syndrome were analysed. 


\section{Results}

Out of the participants, $34.3 \%(n=1181)$ met the criteria of metabolic syndrome. As shown in Table 1 , the percentage of females with MetS was more than the percentage of males $(p<0.01)$. The mean age of MetS participants was older than that of non-MetS participants. The other factors, including smoking status, alcohol consumption, sedentary lifestyle, living status, and depression status were not significantly different in two groups.

Of the sleep symptoms, only difficulty falling asleep (DFA) had a higher prevalence in MetS participants compared to non-MetS participants $(p=0.01$ ) (Table 2$)$. Insomnia syndrome, combined insomnia symptoms, and insomnia duration were not correlated with the occurrence of metabolic syndrome.

Table 1. Sample characteristics according to the presence or absence of the MetS $(\mathrm{N}=1181)$.

\begin{tabular}{|c|c|c|c|}
\hline & Non-MetS (776, 65.7\%) & MetS $(405,34.3 \%)$ & $\mathrm{p}$ value \\
\hline Gender (n, \%) & & & $<0.01^{\dagger}$ \\
\hline Male & 322 (41.5) & $111(27.4)$ & \\
\hline Female & 454 (58.5) & 294 (72.6) & \\
\hline Age (mean \pm SD) & $74.1 \pm 5.5$ & $74.9 \pm 5.5$ & $0.03^{*}$ \\
\hline \multicolumn{4}{|l|}{ Personal habits (n, \%) } \\
\hline Curent/past smoking & $30(3.9)$ & $13(3.2)$ & 0.57 \\
\hline$\geq 4$ drinks/week alcohol drinking & $80(10.3)$ & $45(11.2)$ & 0.55 \\
\hline Sedentary lifestyle & $74(9.5)$ & $48(12.0)$ & 0.20 \\
\hline Living status (n, \%) & & & 0.67 \\
\hline Single & $61(7.9)$ & $38(9.4)$ & \\
\hline With family & $715(92.1)$ & 367 (90.6) & \\
\hline Depression (BSRS-5 $\geq 6$ ) & 95 (12.3\%) & $51(12.6 \%)$ & 0.95 \\
\hline
\end{tabular}

Statistic analysis: Student's t test, fisher's exact test and chi-square test was used, compare with non-MetS and MetS group. ${ }^{*}$ Means $\mathrm{p}<0.05$, ${ }^{\dagger}$ Means $\mathrm{p}<0.01$.

Table 2. Sleep characteristics according to the present or absent of the MetS ( $\mathrm{N}=1181)$.

\begin{tabular}{|c|c|c|c|}
\hline Character & Non-MetS 776 (65.7\%) & MetS 405 (34.3\%) & $\mathrm{p}$ value \\
\hline Insomnia syndrome (n, \%) & $321(41.4)$ & $186(46.0)$ & 0.13 \\
\hline A. Insomnia symptoms & & & 0.49 \\
\hline a. 1 symptom only & $228(29.4)$ & $131(32.3)$ & \\
\hline Combined 2 symptoms & $73(9.4)$ & $39(9.6)$ & \\
\hline Combined 3 symptoms & $13(1.7)$ & $11(2.7)$ & \\
\hline Combined 4 symptoms & $7(0.9)$ & $5(1.4)$ & \\
\hline b. Difficulty falling sleep & $189(24.3)$ & $127(31.3)$ & $0.01^{*}$ \\
\hline c. Difficulty staying sleep & $138(17.8)$ & $66(16.2)$ & 0.49 \\
\hline d. Non-refreshing sleep & $34(4.4)$ & $15(3.8)$ & 0.61 \\
\hline e. Frequent awaking from sleep or dreamy & $71(9.1)$ & 47 (11.6) & 0.17 \\
\hline B. Insomnia duration & & & 0.64 \\
\hline Less than 1 month & $51(6.6)$ & $24(6.1)$ & \\
\hline 1 month $-1 / 2$ year & $31(4.0)$ & $19(4.8)$ & \\
\hline $1 / 2$ year - 1 year & $44(5.7)$ & $26(6.4)$ & \\
\hline 1 year -3 years & $70(9.0)$ & $40(9.9)$ & \\
\hline More than 3 years & $125(16.1)$ & 76 (18.8) & \\
\hline
\end{tabular}

Chi-square test. ${ }^{*}$ Means $\mathrm{p}<0.05{ }^{\dagger}$ Means $\mathrm{p}<0.01$. Insomnia syndrome, included at least 1 insomnia symptoms: difficulty falling asleep, difficulty staying asleep, sleep is not refreshing, or frequent waking from sleep or dreamy, with a frequency criteria of $\geq 3$ times per week. 
In the multivariate logistic regression models (Table 3), which accounted for each of the insomnia symptoms or insomnia duration (adjusted for age, sex, living status, smoking status, alcohol consumption, sedentary lifestyle, and depression status). DFA significantly increase the risk of MetS (OR = 1.42, 95\% CI: $1.09-1.86, \mathrm{P}=$ 0.01). The remaining insomnia symptoms and the syndromic definition of insomnia were unrelated to the risk of the MetS.

Table 4 showed that analyses of the individual metabolic syndrome components revealed that DFA and frequent waking from sleep or dreamy increased the risk of abdominal obesity (DFA: OR $=1.36,95 \%$ CI: 1.05 1.76; frequent awaking: OR $=1.68,95 \% \mathrm{CI}: 1.14-2.49$ ), and DFA increased the risk of hyperglycemia and high triglycerides (OR $=1.43,95 \%$ CI: $1.01-1.82$; OR $=1.67$, 95\% CI: $1.23-2.25$ ); and difficulty staying sleep increased the risk of hypertension ( $\mathrm{OR}=1.39,95 \% \mathrm{CI}: 1.14$ - 1.90). Another insomnia symptoms (non-refreshing sleep) did not increase any of the individual metabolic abnormalities. In this model, we had adjusted for the covariates, including: age, sex, living status (with family/single), smoking status (current or past/never), alcohol consumption ( 0 - 3 drinks per week/4 or more drinks per week), sedentary lifestyle (yes/no), and depression status (score $\geq 6 /<6$ ).

Table 3. Odds ratios of sleep characteristics according to the present or absent of the MetS with covariate adjustment.

\begin{tabular}{lcc}
\hline Character & OR $(95 \% \mathrm{CI})$ & $\mathrm{p}$ value \\
\hline Insomnia symptom (ref: no) & & $0.01^{*}$ \\
Difficulty falling sleep & $1.42(1.09-1.86)$ & 0.38 \\
Difficulty staying sleep & $0.89(0.64-1.24)$ & 0.45 \\
Non-refreshing sleep & $0.85(0.46-1.59)$ & 0.20 \\
Frequent awaking from sleep or dreams & $1.32(0.89-1.95)$ & 0.99 \\
Insomnia duration (ref: no) & & 0.34 \\
Less than 1 month & $1.00(0.60-1.66)$ & 0.43 \\
1 month - $1 / 2$ year & $1.34(0.74-2.4)$ & 0.41 \\
$1 / 2$ year - 1 year & $1.23(0.73-2.07)$ & 0.14 \\
1 year - 3 years & $1.20(0.78-1.83)$ & $1.28(0.92-1.78)$ \\
More than 3 years & & \\
\hline
\end{tabular}

Multivariate logistic regression. ${ }^{*}$ Means $\mathrm{p}<0.05$, ${ }^{\dagger}$ Means $\mathrm{p}<0.01$. Odds ratios are adjusted for covariates including: age, sex, living status (with family/single), smoking status (current or past/never), alcohol consumption ( 0 - 3 drinks per week/ $\geq 4$ drinks per week), sedentary lifestyle (yes/no), and depression status (score $\geq 6 /<6)$.

Table 4. Odds ratios of risk factors of MetS according to sleep characters.

\begin{tabular}{|c|c|c|c|c|c|c|c|c|c|c|c|c|c|c|c|}
\hline & \multicolumn{3}{|c|}{ AO (581, 49.2\%) } & \multicolumn{3}{|c|}{ HT $(678,67.4 \%)$} & \multicolumn{3}{|c|}{ HDL-C (229, 19.4\%) } & \multicolumn{3}{|c|}{ HG $(626,53.0 \%)$} & \multicolumn{3}{|c|}{ HTG $(258,21.8 \%)$} \\
\hline & $\mathrm{N}$ & $\begin{array}{c}\text { OR } \\
(95 \% \mathrm{CI})\end{array}$ & $\begin{array}{c}\mathrm{p} \\
\text { value }\end{array}$ & $\mathrm{N}$ & $\begin{array}{c}\text { OR } \\
(95 \% \mathrm{CI})\end{array}$ & $\begin{array}{c}\mathrm{p} \\
\text { value }\end{array}$ & $\mathrm{N}$ & $\begin{array}{c}\text { OR } \\
(95 \% \mathrm{CI})\end{array}$ & $\begin{array}{c}\mathrm{p} \\
\text { value }\end{array}$ & $\mathrm{N}$ & $\begin{array}{c}\text { OR } \\
(95 \% \mathrm{CI})\end{array}$ & $\begin{array}{c}\mathrm{p} \\
\text { value }\end{array}$ & $\mathrm{N}$ & $\begin{array}{c}\text { OR } \\
(95 \% \mathrm{CI})\end{array}$ & $\begin{array}{c}\mathrm{p} \\
\text { value }\end{array}$ \\
\hline $\begin{array}{l}\text { Difficulty } \\
\text { staying } \\
\text { sleep }\end{array}$ & $\begin{array}{c}90 \\
(15.5)\end{array}$ & $\begin{array}{c}0.79 \\
(0.58-1.07)\end{array}$ & 0.121 & $\begin{array}{c}137 \\
(20.2)\end{array}$ & $\begin{array}{c}1.39 \\
(1.14-1.90)\end{array}$ & $0.021^{*}$ & $\begin{array}{c}33 \\
(14.4)\end{array}$ & $\begin{array}{c}0.76 \\
(0.52-1.09)\end{array}$ & 0.138 & $\begin{array}{c}107 \\
(17.1)\end{array}$ & $\begin{array}{c}0.98 \\
(0.72-1.33)\end{array}$ & 0.886 & $\begin{array}{c}49 \\
(19.0)\end{array}$ & $\begin{array}{c}1.17 \\
(0.82-1.68)\end{array}$ & 0.386 \\
\hline $\begin{array}{l}\text { Non- } \\
\text { refreshing } \\
\text { sleep }\end{array}$ & $\begin{array}{c}24 \\
(4.2)\end{array}$ & $\begin{array}{c}1.01 \\
(0.57-1.79)\end{array}$ & 0.979 & $\begin{array}{c}24 \\
(3.6)\end{array}$ & $\begin{array}{c}0.70 \\
(0.39-1.23)\end{array}$ & 0.210 & $\begin{array}{c}7 \\
(3.1)\end{array}$ & $\begin{array}{c}0.66 \\
(0.32-1.38)\end{array}$ & 0.270 & $\begin{array}{c}32 \\
(5.0)\end{array}$ & $\begin{array}{c}1.57 \\
(0.87-2.84)\end{array}$ & 0.132 & $\begin{array}{c}12 \\
(4.8)\end{array}$ & $\begin{array}{c}1.19 \\
(0.61-2.32)\end{array}$ & 0.606 \\
\hline $\begin{array}{l}\text { Frequent } \\
\text { awaking } \\
\text { from sleep } \\
\text { or dreams }\end{array}$ & $\begin{array}{c}71 \\
(12.3)\end{array}$ & $\begin{array}{c}1.68 \\
(1.14-2.49)\end{array}$ & $0.009^{\dagger}$ & $\begin{array}{c}70 \\
(10.3)\end{array}$ & $\begin{array}{c}1.09 \\
(0.74-1.61)\end{array}$ & 0.663 & $\begin{array}{c}24 \\
(10.3)\end{array}$ & $\begin{array}{c}1.05 \\
(0.68-1.63)\end{array}$ & 0.826 & $\begin{array}{c}62 \\
(9.9)\end{array}$ & $\begin{array}{c}0.99 \\
(0.68-1.46)\end{array}$ & 0.980 & $\begin{array}{c}25 \\
(9.5)\end{array}$ & $\begin{array}{c}0.84 \\
(0.59-1.51)\end{array}$ & 0.803 \\
\hline
\end{tabular}

Multivariate logistic regression. ${ }^{*}$ Means $\mathrm{p}<0.05,{ }^{\dagger}$ Means $\mathrm{p}<0.01$. Adjust covariates including: age, sex, living status (with family/single), smoking status (current or past/never), alcohol consumption ( 0 - 3 drinks per week $/ \geq 4$ drinks per week), sedentary lifestyle (yes/no), and depression status (score $\geq 6 /<6$ ). Abbreviation: AO—abdominal obesity (waist circumference, $\geq 90 \mathrm{~cm}$ for men and $\geq 80 \mathrm{~cm}$ for women), HT-hypertension (systolic BP, $\geq 130$, diastolic BP, $\geq 85$ $\mathrm{mmHg}$, or the use of antihypertensive agents); HDL-C—low serum HDL-C ( $\leq 40 \mathrm{mg} / \mathrm{dl}$ for men and $\leq 50 \mathrm{mg} / \mathrm{dl}$ for women), HTG-hypertriglyceremia (TG, $\geq 150 \mathrm{mg} / \mathrm{dl}$ ), $\mathrm{HG}$ - hyperglycemia (fasting plasma glucose, $\geq 100 \mathrm{mg} / \mathrm{dl}$ or the use of anti-hyperglycemic agents). 


\section{Discussion}

In this cross-section study, we found that difficulty falling asleep (DFA) increased the risk of MetS in the elderly from a northern Taiwanese community $(\mathrm{OR}=1.42,95 \% \mathrm{CI}$ : $1.09-1.86, \mathrm{P}=0.01)$. According to a prospective American study published in 2010 (middle-aged adults in community) that found DFA increased the risk of MetS by $80 \%$, even after adjusting for demographic, psychosocial, and lifestyle characteristics [14]. These results raise the possibility that clinical insomnia complaints may be a causal risk factor for cardiometabolic dysfunction in adult. However, this study did not address this issue in an elderly population. Our previous study proved that DFA and unhealthy personsal sleep hygiene increased the number of MetS risk factors [20], and another goal that provides data regarding the impact of common insomnia problems on the risk factors of MetS among the elderly population in northern Taiwan in this paper.

Indeed, our data suggest that DFA, which may be an isolated insomnia disturbance, or a symptom related to any one of several sleep disorders, increased the risk for the MetS; but, the syndromic definition of insomnia was unrelated to MetS. Other insomnia symptoms, such as difficulty staying sleep, non-refreshing sleep, or frequent waking from sleep or dreamy, were independent of MetS even after accounting for the influence of insomnia duration. The results was partially mimic with previous paper, but in our study we did not focus on the snoring symptom which was found in another study, inclunding loud snoring more than doubled the risk of developing the metabolic syndrome and also predicted specific metabolic abnormalities (hyperglycemia and low high-density lipoprotein cholesterol) [14]. In our study, we focused on subjective insomnia symptoms, snorning symptom was belong to objective description which need be observated by roomates.

Prolonged sleep latency and short sleep duration may reflect a state of inappropriate arousal ("hyperarousal") due to an overactivation of stress system functions [28]-[30], these physical changes have been implicated in the pathophysiology of insulin resistance and MetS. Evidence suggests that DFA is associated with the activation of transcription factor (NF)-kB, which plays a critical role in cellular inflammatory signaling [29]-[31]. This pathway leading to increased inflammatory response may link DFA with the development of the MetS, diabetes and other chronic diseases [32]. We speculate that pathways linking these insomnia symptoms with metabolic dysregulation might be due to sympathetic activation and increased inflammatory response [14].

Moreover, our findings link DFA and frequent waking from sleep or dreamy with an increased risk of abdominal obesity. DFA was also correlated with the increased risk of hyperglycemia and high triglyceride, and difficulty staying sleep increased the risk of hypertension. Previous analysis shows that experimental sleep deprivation, short sleep duration, and persistent insomnia are associated with increased blood pressure and increased risk of hypertension, even after controlling for other risk factors [30] [33]. Poor sleep quantity, including longer sleep latency and inappropriate sleep duration increased the risk of abnormal body weight gain [34] and central obesity [35] [36]. In the Japanese study, women getting fewer than 6 hours of sleep on a regular basis had higher triglycerides and lower HDL-cholesterol than those getting 6 to 7 hours of sleep a night. Many of those men and women who slept fewer than 6 hours also reported in the study that they skipped meals, ate out once or more per day, and/or experienced high levels of psychological stress [37].

In another 2-year prospective study of Japanese local residents (2005-2007), a total of 497 residents participated in this survey living in a rural community, the result showed that DFA is a risk factor for hyperglycemia $(\mathrm{OR}=5.27,95 \%$ CI: $1.48-18.77, \mathrm{p}=0.01)$ [38]. Several studies have revealed that insomnia increases the blood catecholamines and cortisol concentration and insulin resistance [39] [40]. Previous epidemiological cross-sectional studies and several prospective studies in Western countries mentioned that many sleep symptoms, such as DFA, difficulty in maintaining sleep , and remaining alert, is higher in patients with diabetes [41][43].

Recent studies have revealed that depression could be a confounding factor in the association between hyperglycemia and sleep disorders [44]. In our study, depression status was used as a covariate.

These insomnia symptoms, including DFA, difficulty staying sleep, and frequent waking from sleep or dreamy increased the odds ratio of risk factors. Evaluating insomnia symptoms can help identify individuals at risk for MetS. The lack of a relationship between insomnia syndrome and MetS may have important treatment implications, as worries about the health consequences of insomnia are a key risk factor in the disorder [45]. Recent evidence suggests that the presence of insomnia in conjunction with a physiologic indicator of disease severity strongly and significantly predicts hypertension risk, suggesting that different symptoms of insomnia may represent a higher threshold of risk, and this may be relevant in the prediction of cardiovascular outcomes [46]. 
An incomplete cross-sectional survey is a limitation of this study. We were only able to assess the aging population of a particular region of the northern metropolitan area, and this population may not be representative of the entire elderly population. The prevalence of MetS might be underestimated for some elderly individuals who may go to the medical center to receive physical examinations on their own, as they might pay more attention to their health than other elderly. The specific risk factors assessed in this study may have been found in the elderly population that has access to medical treatment and could be regarded as warranting intervention. Thus, these treated individuals would be precluded from our study population.

\section{Conclusion}

Our study provides evidence to support the relationship between commonly reported insomnia symptomsincluding difficulty falling asleep, difficulty staying sleep, and frequent waking from sleep and dreamy —and the risk of the MetS. Insomnia syndrome, defined using the Chinese version of the Athens Insomnia Scale (CAIS) as diagnostic criteria, was not a risk factor for metabolic syndrome. Given that in the general elderly population insomnia complaints are considerably more prevalent than either insomnia or obstructive sleep apnea syndromes, these findings have far-reaching implications for public health. This is particularly important given the epidemic levels of obesity and its associated cardiometabolic consequences, which are associated with insomnia complaints. These findings reflect the utility of assessing for common insomnia complaints in routine clinical practice, as individuals that report such insomnia-associated symptoms may be at elevated risk for the development of MetS.

\section{Disclosure of Conflicts of Interest}

I certify that all my affiliations with or financial involvement in, within the past 5 years and foreseeable future, any organization or entity with a financial interest in or financial conflict with the subject matter or materials discussed in the manuscript are completely disclosed (e.g., employment, consultancies, honoraria, stock ownership or options, expert testimony, grants or patents received or pending, royalties).

\section{References}

[1] Department of Health (2011) The Executive Yuan. Statistics Report, Taiwan.

[2] Yao, C.A., Lee, L.T., Chen, C.Y. and Huang, K.C. (2005) The Study of Metabolic Syndrome in Elderly Receiving Health Check-Up. Taiwan Geriatrics \& Gerontology, 1, 18-25.

[3] Lakka, H.M., Laaksonen, D.E., Lakka, T.A., Niskanen, L.K., Kumpusalo, E., Tuomilehto, J. and Salonen, J.T. (2002) The Metabolic Syndrome and Total and Cardiovascular Disease Mortality in Middle-Aged Men. JAMA, 288, 27092716. http://dx.doi.org/10.1001/jama.288.21.2709

[4] Hung, T.C., Chen, C.Y., Cheng, S.J., Liu, C.H. and Yeh, H.I. (2009) Comparison of the Prevalence of Metabolic Syndrome between the Criteria for Taiwanese and Japanese and the Projected Probability of Stroke in Elderly Hypertensive Taiwanese. International Journal of Gerontology, 3, 233-240. http://dx.doi.org/10.1016/S1873-9598(10)70006-5

[5] Lin, Y.H., Chang, H.T., Tseng, Y.H., Lin, M.H., Chen, Y.C., Yang, H.W. and Hwang, S.J. (2013) Characteristics and Health Behavior of Newly Developed Metabolic Syndrome among Community-Dwelling Elderly in Taiwan. International Journal of Gerontology, 7, 90-96. http://dx.doi.org/10.1016/j.ijge.2012.07.003

[6] Huang, K.C., Lee, M.S., Lee, S.D., Chang, Y.H., Lin, Y.C., Tu, S.H. and Pan, W.H. (2005) Obesity in the Elderly and Its Relationship with Cardiovascular Risk Factors in Taiwan. Obesity Research, 13, 170-178. http://dx.doi.org/10.1038/oby.2005.22

[7] Tsai, H.J. and Tsai, A.C. (2012) Prevalence of Metabolic Syndrome in Elderly Taiwanese: Results from the Nutrition and Health Survey in Taiwan (1999-2000). http://apha.confex.com/apha/135am/techprogram/paper_150632.htm

[8] Reichmuth, K.J., Austin, D., Skatrud, J.B. and Young, T. (2005) Association of Sleep Apnea and Type 2 Diabetes: A Population-Based Study. American Journal of Respiratory and Critical Care Medicine, 172, 1590-1595. http://dx.doi.org/10.1164/rccm.200504-637OC

[9] Ayas, N.T., White, D.P., Al-Delaimy, W.K., Manson, J.E., Stampfer, M.J., Speizer, F.E. and Hu, F.B. (2003) A Prospective Study of Self-Reported Sleep Duration and Incident Diabetes in Women. Diabetes Care, 26, 380-384. http://dx.doi.org/10.2337/diacare.26.2.380

[10] Gangswich, J.E., Heymsfield, S.B., Boden-Albala, B., Buijs, R.M., Kreier, F., Pickering, T.G. and Malaspina, D. (2007) Sleep Duration as a Risk Factor for Diabetes Incidence in a Large U.S. Sample. Sleep, 30, 1667-1673. 
[11] Kawakami, N., Takatsuka, N. and Schimizu, H. (2004) Sleep Disturbance and Onset of Type 2 Diabetes. Diabetes Care, 27, 282-283. http://dx.doi.org/10.2337/diacare.27.1.282

[12] Nilsson, P.M., Roost, M., Engstrom, G., Hedblad, B. and Berglund, G. (2004) Incidence of Diabetes in Middle-Aged Men Is Related to Sleep Disturbances. Diabetes Care, 27, 2464-2469. http://dx.doi.org/10.2337/diacare.27.10.2464

[13] O’Connor, G.T., Caffo, B., Newman, A.B., Quan, S.F., Rapoport, D.M., Redling, S. and Shahar, E. (2009) Prospective Study of Sleep-Disordered Breathing and Hypertension. American Journal of Respiratory and Critical Care Medicine, 179, 1159-1164. http://dx.doi.org/10.1164/rccm.200712-1809OC

[14] Troxel, W.M., Buysse, D.J., Matthews, K.A., Kip, K.E., Strollo, P.J., Hall, M. and Reis, S.E. (2010) Sleep Symptoms Predict the Development of the Metabolic Syndrome. Sleep, 33, 1633-1640.

[15] Gruber, A., Howrwood, F., Sithole, J., Ali, N.J. and Idris, I. (2006) Obstructive Sleep Apnoea Is Independently Associated with the Metabolic Syndrome but Not Insulin Resistance State. Cardiovascular Diabetology, 5, 1-7. http://dx.doi.org/10.1186/1475-2840-5-1

[16] Hall, M.H., Muldoon, M.F., Jennings, J.R., Buysse, D.J., Flory, J.D. and Manuck, S.B. (2008) Self-Reported Sleep Duration Is Associated with the Metabolic Syndrome in Midlife Adults. Sleep, 31, 635-643.

[17] Jennings, J.R., Muldoon, M.F., Hall, M., Buysse, D.J. and Manuck, S.B. (2007) Self-Reported Sleep Quality Is Associated with the Metabolic Syndrome. Sleep, 30, 219-223.

[18] Leineweber, C., Kecklund, G., Åkerstedt, T., Janszky, I. and Orth-Gomér, K. (2003) Snoring and the Metabolic Syndrome in Women. Sleep Medicine, 4, 531-536. http://dx.doi.org/10.1016/S1389-9457(03)00160-6

[19] Tsou, M.T. (2012) Sleep Duration and Obesity among Adults under 65 Years of Age and the Elderly in Taiwan. International Journal of Gerontology, 6, 27-32. http://dx.doi.org/10.1016/j.ijge.2011.09.027

[20] Tsou, M.T. (2014) The Association between Metabolic Syndrome and Sleep Symptoms and Sleep Hygiene in the Elderly in Northern Taiwan. AAR, 3, No. 1.

[21] Chiang, H.L., Chen, H.C., Bai, C.H., Che, H.H., Lee, M.B., Lai, S.H. and Chou, P. (2009) A Validation Study of the Chinese Version of the Athens Insomnia Scale. Taiwan Journal of Psychology, 23, 43-52.

[22] Bureau of Health Promotion Database (2014) The Criteria of Metabolic Syndrome. http://www.youth.com.tw/db/epaper/es002001/eb2403.htm

[23] Hwang, L.C., Bai, C.H. and Chen, C.J. (2006) Prevalence of Obesity and Metabolic Syndrome in Taiwan. Journal of the Formosan Medical Association, 105, 626-635. http://dx.doi.org/10.1016/S0929-6646(09)60161-3

[24] Bureau of Health Promotion, Department of Health, Taiwan (2015) The Method of Measuring Waist Circumference of Adult. http://www.hpa.gov.tw/BHPNet/Web/HealthTopic/TopicArticle.aspx?No=200712250120\&parentid=200712250023

[25] Lee, M.B., Liao, S.C., Lee, Y.J., Wu, C.H., Tseng, M.C., Gau, S.F. and Rau, C.L. (2003) Development and Verification of Validity and Reliability of a Short Screening Instrument to Identify Psychiatric Morbidity. Journal of the Formosan Medical Association, 102, 687-694.

[26] Chen, H.C., Wu, C.H., Lee, Y.J., Liao, S.C. and Lee, M.B. (2005) Validity of the Five-Item Brief Symptom Rating Scale among Subjects Admitted for General Health Screening. Journal of the Formosan Medical Association, 104, 824-829.

[27] Ainsworth, B.E., Jacobs, D.R. and Leon, A.S. (1993) Validity and Reliability of Self-Reported Physical Activity Status: The Lipid Research Clinics Questionnaire. Medicine \& Science in Sports \& Exercise, 25, 92-98. http://dx.doi.org/10.1249/00005768-199301000-00013

[28] Zhan, Y., Zhang, F., Lu, L., Lu, L., Wang, J., Sun, Y., Ding, R. and Yu, J. (2014) Prevalence of Dyslipidemia and Its Association with Insomnia in a Community Based Population in China. BMC Public Health, 14, 1050. http://dx.doi.org/10.1186/1471-2458-14-1050

[29] Vgontzas, A.N. and Chrousos, G.P. (2002) Sleep, the Hypothalamic-Pituitary-Adrenal Axis, and Cytokines: Multiple Interactions and Disturbances in Sleep Disorders. Endocrinology Metabolism Clinics of North America, 31, 15-36. http://dx.doi.org/10.1016/S0889-8529(01)00005-6

[30] Palagini, L., Bruno, R.M., Gemignani, A., Baglioni, C., Ghiadoni, L. and Riemann, D. (2013) Sleep Loss and Hypertension: A Systematic Review. Current Pharmaceutical Design, 19, 2409-2419. http://dx.doi.org/10.2174/1381612811319130009

[31] Irwin, M.R., Wang, M., Ribeiro, D., Cho, H.J., Olmstead, R.M., Breen, E.C. and Cole, S. (2008) Sleep Loss Activates Cellular Inflammatory Signaling. Biological Psychiatry, 64, 538-540. http://dx.doi.org/10.1016/j.biopsych.2008.05.004

[32] Dew, M.A., Hoch, C.C., Buysse, D.J., Monk, T.H., Begley, A.E., Houck, P.R. and Reynolds III, C.F. (2003) Healthy Older Adults' Sleep Predicts All-Cause Mortality at 4 to 19 Years of Follow-Up. Psychosomatic Medicine, 65, 63-73. http://dx.doi.org/10.1097/01.PSY.0000039756.23250.7C 
[33] Bruno, R.M., Palagini, L., Gemignani, A., Virdis, A., Di, G.A., Ghiadoni, L. and Taddei, S. (2013) Poor Sleep Quality and Resistant Hypertension. Sleep Medicine, 14, 1157-1163.

[34] Lallukka, T., Haario, P., Lahelma, E. and Rahkonen, O. (2012) Associations of Relative Weight with Subsequent Changes over Time in Insomnia Symptoms: A Follow-Up Study among Middle-Aged Women and Men. Sleep Medicine, 13, 1271-1279.

[35] Theorell-Haglöw, J., Berglund, L., Janson, C. and Lindberg, E. (2012) Sleep Duration and Central Obesity in Women-Differences between Short Sleepers and Long Sleepers. Sleep Medicine, 13, 1079-1085. http://dx.doi.org/10.1016/j.sleep.2012.06.013

[36] Theorell-Haglöw, J., Berne, C., Janson, C., Sahlin, C. and Lindberg, E. (2010) Associations between Short Sleep Duration and Central Obesity in Women. Sleep, 33, 593-598.

[37] Kaneita, Y., Uchiyama, M., Yoshiike, N. and Ohida, T. (2008) Associations of Usual Sleep Duration with Serum Lipid and Lipoprotein Levels. Sleep, 31, 645-652.

[38] Nakajima, H., Kaneita, Y., Yokoyama, E., Tamak, T., Munezawa, T., Matsuzaka, M. and Ohida, T. (2010) Insomnia Symptoms Associated with Hyperglycemia. Sleep and Biological Rhythms, 8, 203-211. http://dx.doi.org/10.1111/j.1479-8425.2010.00449.x

[39] Hjemdahil, P. (2002) Stress and Metabolic Syndrome. Circulation, 106, 2634-2636. http://dx.doi.org/10.1161/01.CIR.0000041502.43564.79

[40] Spiegel, K., Knutson, K., Leproult, R., Tasali, E. and Cauter, E.V. (2005) Sleep Loss: A Novel Risk Factor for Insulin Resistance and Type 2 Diabetes. Journal of Applied Physiology, 99, 2008-2019. http://dx.doi.org/10.1152/japplphysiol.00660.2005

[41] Mallon, L., Broman, J.E. and Hetta, J. (2005) High Incidence of Diabetes in Men with Sleep Complaints or Short Sleep Duration: A 12-Year Follow-Up Study of a Middle-Aged Population. Diabetes Care, 28, 2762-2767. http://dx.doi.org/10.2337/diacare.28.11.2762

[42] Markku, T. and Hyyppa, E.K. (1989) Quality of Sleep and Chronic Illnesses. Journal of Clinical Epidemiology, 42, 633-638. http://dx.doi.org/10.1016/0895-4356(89)90006-1

[43] Gottlieb, D.J., Punjabi, N.M., Newman, A.B., Resnick, H.E., Redline, S., Baldwin, C.M. and Nieto, F.J. (2005) Association of Sleep Time with Diabetes Mellitus and Impaired Glucose Tolerance. Archives of Internal Medicine, 165, 863-867. http://dx.doi.org/10.1001/archinte.165.8.863

[44] Knol, M.J., Twisk, J.W.R., Beekman, A.T.F., Heine, R.J., Snoek, F.J. and Pouwer, F. (2006) Depression as a Risk Factor for the Onset of Type 2 Diabetes: A Meta-Analysis. Diabetologia, 49, 837-845. http://dx.doi.org/10.1007/s00125-006-0159-x

[45] Harvey, A.G. and Greenall, E. (2003) Catastrophic Worry in Primary Insomnia. Journal of Behavior Therapy and Experimental Psychiatry, 34, 11-23. http://dx.doi.org/10.1016/S0005-7916(03)00003-X

[46] Vgontzas, A.N., Liao, D., Bixler, E.O., Chrousos, G.P. and Vela-Bueno, A. (2009) Insomnia with Objective Short Sleep Duration Is Associated with a High Risk for Hypertension. Sleep, 32, 491-497. 


\section{Appendix 1 [21]}

Chinese Athens insomnia scale-5.

\begin{tabular}{|c|c|c|c|c|}
\hline Sleep factors & & Chines & thens insomnia scale-5 & \\
\hline Difficulty falling sleep & 0: No problem & 1: Slightly delayed & 2: Markedly delayed & $\begin{array}{l}\text { 3: Very delayed or did not } \\
\text { sleep at all }\end{array}$ \\
\hline Difficulty staying sleep & 0: No problem & 1: Minor problem & 2: Considerable problem & $\begin{array}{l}\text { 3: Serious problem or did } \\
\text { not sleep at all }\end{array}$ \\
\hline Non-refreshing sleep & 0: Satisfactory & 1: Slightly unsatisfactory & 2: Markedly unsatisfactory & $\begin{array}{l}\text { 3: Very unsatisfactory or } \\
\text { did not sleep at all }\end{array}$ \\
\hline $\begin{array}{l}\text { Frequent awaking from } \\
\text { sleep or dreams }\end{array}$ & 0: Not earlier & 1: A little earlier & 2: Markedly earlier & $\begin{array}{l}\text { 3: Much earlier or did not } \\
\text { sleep at all }\end{array}$ \\
\hline Total sleep duration & 0: Sufficient & 1: Slightly insufficient & 2: Markedly insufficient & $\begin{array}{l}\text { 3: Very insufficient or did } \\
\text { not sleep at all }\end{array}$ \\
\hline
\end{tabular}

\section{Appendix 2 [25] [26]}

Brief Symptom Rating Scale (BSRS-5).

Instruction: How much were you bothered by each of the following items during the past week, including the current day? Please circle the number best describes your feeling about the item.

0: not at all 1: a little bit 2: moderately 3: quite a bit 4: extremely

1) Feeling tense or keyed up....................

2) Feeling blue..............................

12

3) Feeling easily annoyed or irritable...........0

12

4) Feeling infereior to others..................0

12

5) Trouble falling asleep........................

23

